\begin{tabular}{|c|l|}
\hline Title & $\begin{array}{l}\text { Vapochromic luminescent proton conductors: switchable vapochromism and proton conduction of luminescent Pt(ii) } \\
\text { complexes with proton- exchangeable sites }\end{array}$ \\
\hline Author(s) & Kobay ashi, A tsushi; Imada, Shin-ichiro; Shigeta, Y asuhiro; Nagao, Y uki; Y oshida, Masaki; Kato, Masako \\
\hline Citation & $\begin{array}{l}\text { Journal of materials chemistry C, 7(47), 14923-14931 } \\
\text { https://doi.org/10.1039/c9tc04944d }\end{array}$ \\
\hline Issue Date & 2019-12-21 \\
\hline Doc URL & http://hdl.handle.net/2115/80010 \\
\hline Type & article (author version) \\
\hline File Information & J. mate chem 47 2019.pdf \\
\hline
\end{tabular}

Instructions for use 
Received 00th January 20xx, Accepted 00th January 20xx DOI: $10.1039 / x 0 x \times 00000 x$

\title{
Vapochromic Luminescent Proton Conductors: Switchable Vapochromism and Proton Conduction of Luminescent Pt(II) Complexes with Proton-exchangeable Sites
}

\begin{abstract}
Atsushi Kobayashi, ${ }^{\text {a }}$ Shin-ichiro Imada, ${ }^{a}$ Yasuhiro Shigeta, ${ }^{\text {a }}$ Yuki Nagao, ${ }^{b}$ Masaki Yoshida, ${ }^{a}$ and Masako Kato*a

Two luminescent and highly proton-conductive $\mathrm{Pt}(\mathrm{II})$ complexes, $\left[\mathrm{PtCl}(\right.$ tpypy) $] \mathrm{Cl}$ and $[\mathrm{PtCl}(\mathrm{tpypyH})] \mathrm{Cl}_{2}(\mathbf{1}$ and $\mathbf{1} \cdot \mathbf{H C l}$, respectively; tpypy $=2,2^{\prime}: 6^{\prime}, 2^{\prime \prime}$-terpyridine- $4^{\prime}, 4^{\prime \prime \prime}$-pyridine) were successfully synthesized. $\mathrm{X}$-ray analysis revealed that the intermolecular Pt...Pt interaction was ineffective in the monohydrated form of $\mathbf{1} \cdot \mathbf{H}_{2} \mathbf{O}$ but effective in the dihydrate and hexahydrate forms, 1. $\mathbf{H C l} \cdot n \mathrm{H}_{2} \mathbf{O}\left(n=2\right.$ and 6). Yellow luminescence $\left(\lambda_{\mathrm{em}}=519 \mathrm{~nm}, \Phi=0.016\right)$ assigned to intraligand ${ }^{3} \pi-\pi^{*}$ phosphorescence was observed for $\mathbf{1} \cdot \mathbf{H}_{\mathbf{2}} \mathbf{O}$, whereas a stronger red emission ascribable to the phosphorescence from the

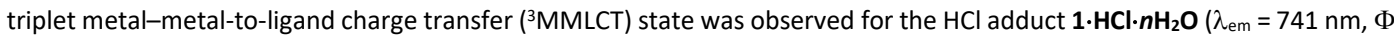
$=0.06$ for $\boldsymbol{n}=2, \lambda_{\mathrm{em}}=642 \mathrm{~nm}$, and $\Phi=0.10$ for $\boldsymbol{n}=6$ ). Both complexes exhibited strong relative humidity (RH)-dependent proton conductivity, while surprisingly high conductivity was observed for $1 \cdot \mathbf{H C l}\left(6.8 \times 10^{-3} \mathrm{~S} \mathrm{~cm}^{-1}\right)$ at $95 \% \mathrm{RH}$ at $298 \mathrm{~K}$. The reversible transformation between $\mathbf{1}$ and $\mathbf{1} \cdot \mathbf{H C l}$ was achieved by exposure to humid $\mathrm{HCl}$ gas and heating and their vapochromic behaviour was completely different owing to the presence of acidic $\mathrm{N}-\mathrm{H}$ protons and the additional hydrophilic $\mathrm{Cl}^{-}$counter anions in $\mathbf{1} \cdot \mathbf{H C l}$. To the best of our knowledge, these complexes are the first switchable vapochromic and highly proton conductive materials that can be employed to visualize the proton conducting state by colour and luminescence.
\end{abstract}

\section{Introduction}

Proton conductors exhibiting high proton conductivity in the solid state are key materials for the fabrication of highperformance fuel cells. ${ }^{1-4}$ To date, various types of proton conductors have been developed, ranging from organic materials ${ }^{5-13}$ with strongly acidic functional groups, such as Nafion, to inorganic oxides ${ }^{14-19}$ such as yttria-doped barium zirconate. In addition to these typical organic and inorganic proton conductors, metal-organic frameworks (MOFs) and related coordination compounds are attracting increasing attention as high proton conductors as well as multifunctional proton conducting materials because of the various techniques that can be employed for their functionalization. ${ }^{20-38}$ Luminescent proton conducting MOFs comprising emissive lanthanide cations are examples of such interesting multifunctional porous materials. ${ }^{34-38}$ For example, Zheng et al. reported that the $f-f$ phosphorescence emission lifetime and

\footnotetext{
a. Department of Chemistry, Faculty of Science, Hokkaido University, North-10 West-8, Kita-ku, Sapporo, Hokkaido 060-0810, Japan.E:mail:

akoba@sci.hokudai.ac.jp (AK), mkato@sci.hokudai.ac.jp (MK)

b. School of Materials Science, Japan Advanced Institute of Science and Technology, 1-1 Asahidai, Nomi, Ishikawa 923-1292, Japan. E-mail: ynagao@jaist.ac.jp

tPresent address: Nanomaterials Research Institute (NanoMaRI), Kanazawa University, Kanazawa 920-1192, Japan.

Electronic Supplementary Information (ESI) available: Hydrogen bonding network structures, emission decays, UV-vis absorption spectral change in solution, excitation and emission spectra at $77 \mathrm{~K}$, PXRD patterns, TG-DTA curves, and ${ }^{1} \mathrm{H}$ NMR spectra. See DOI: 10.1039/x0xx00000x
}

intensity of the proton conductor $\mathrm{Eu}(\mathrm{III})-\mathrm{MOF}$, $\left[\mathrm{Eu}_{2}\left(\mathrm{CO}_{3}\right)(\mathrm{ox})_{2}\left(\mathrm{H}_{2} \mathrm{O}\right)_{2}\right] \cdot 4 \mathrm{H}_{2} \mathrm{O}$ (ox = oxalate), strongly depended on the temperature and hydration number. ${ }^{35}$ Such a cooperative phenomenon between proton conduction and luminescence may enable us to visualize the proton conducting pathway via spectroscopic techniques without using bulk electrodes and to acquire valuable information in complicated systems such as fuel cells. However, the dependence of the $f-f$ emission energy on the coordination structure of the $\mathrm{Ln}^{3+}$ cations is negligible. Thus, to date, the changes in the luminescence behaviour observed in Ln-MOF systems have been insufficient for this purpose. Another noteworthy approach for the visualization of the proton conducting state is the fabrication of hybrid materials comprising proton conducting substrates such as Nafion and suitable dye molecules. ${ }^{39-42}$ However, it is challenging for this technique to achieve both high proton conductivity and a reversible colour/luminescence change because the proton conducting pathway is blocked by the incorporated dye molecules.

To overcome these difficulties, we have focused on luminescent $\mathrm{Pt}$ (II) complexes because these systems have attracted much attention as unique vapochromic materials that exhibit reversible colour and/or luminescence changes in response to reversible vapour adsorption/desorption. ${ }^{42-48}$ One typical example is the simple $\mathrm{Pt}(\mathrm{II})$-diimine complex $\left[\mathrm{Pt}(\mathrm{CN})_{2}(\right.$ bpy $\left.)\right]$ (bpy $=2,2^{\prime}$-bipyridine), which exhibits watervapour-induced vapochromism between the red-luminescent anhydrous state and yellow-emissive monohydrate state. ${ }^{48}$ This phenomenon originates from the structural transformation 

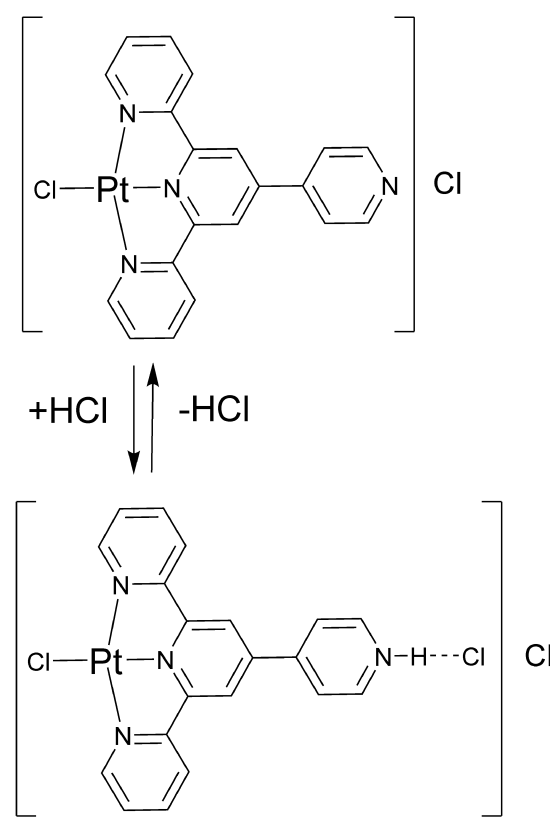

1

\section{$1 \cdot \mathrm{HCl}$}

Scheme 1. Molecular structures and reversible $\mathrm{HCl}$ addition and removal between 1 and $\mathbf{1} \cdot \mathbf{H C l}$.

involving the change in the intermolecular $5 \mathrm{dz}^{2}$ orbital overlap between the adjacent $\mathrm{Pt}(\mathrm{II})$ cations (i.e., metallophilic interaction). ${ }^{42}$ This clearly indicates that luminescent $\mathrm{Pt}(\mathrm{II})$ square-planar chromophores are suitable for the visualization of the proton conducting state, especially of water-mediated proton conductors. Although little attention has been devoted towards luminescent $\mathrm{Pt}$ (II) complexes as proton conducting materials to date, ${ }^{49-51}$ several studies have recently reported on proton conducting $\mathrm{Pt}(\mathrm{II})$ complexes, which exhibit interesting thermochromic and vapochromic luminescence behaviour. Schmidt et al. reported on their thermochromic luminescence and proton conduction behaviour at temperatures above 293 K. ${ }^{49}$ Higuchi et al. also reported on the proton conduction and luminescence behaviour of imidazole-doped $\mathrm{Pt}(\mathrm{II})-$ metallopolymer materials. ${ }^{50}$ However, the proton conductivities of these $\mathrm{Pt}$ (II) complexes were low at room temperature $\left(<10^{-5} \mathrm{~S} \mathrm{~cm}^{-1}\right)$ because of the lack of strongly acidic protons. The luminescence was simply quenched in the proton conducting state, probably because of the thermal deactivation occurring at the high temperatures required to promote proton conduction.

In this work, to design vapochromism linked to proton conduction, we have newly synthesized a luminescent Pt(II)terpyridine complex with a proton-accepting non-coordinated pyridyl group, $[\mathrm{PtCl}($ tpypy) $] \mathrm{Cl}$ (1) and its $\mathrm{HCl}$-adduct $[\mathrm{PtCl}(\mathrm{tpypyH})] \mathrm{Cl}_{2} \quad\left(\mathbf{1} \cdot \mathrm{HCl}\right.$, Scheme 1 ; tpypy = 2,2':6', $\mathbf{2}^{\prime \prime}$ terpyridine- $4^{\prime}, 4^{\prime \prime \prime}$-pyridine). The additional pyridyl group directly attached to the $[\mathrm{PtCl}(\mathrm{tpy})]^{+}$(tpy $=2,2^{\prime}: 6^{\prime}, 2^{\prime \prime}$-terpyridine) moiety was expected to act as both a proton accepting site to produce the cationic and strongly-acidic pyridinium $\mathrm{py}-\mathrm{H}^{+}$ group and an effective switch for the vapochromic behaviour ("switchable vapochromism") 46 of the Pt(II) luminophore based on the protonation process. We demonstrated that these two
Table 1. Selected bond lengths $(\AA)$, bond angles $\left({ }^{\circ}\right)$, and torsion angles $\left({ }^{\circ}\right)$ of $\mathbf{1} \cdot \mathbf{H}_{\mathbf{2}} \mathbf{O}$, 1. $\mathrm{HCl} \cdot 2 \mathrm{H}_{2} \mathrm{O}$, and $1 \cdot \mathrm{HCl} \cdot 6 \mathrm{H}_{2} \mathrm{O}$

\begin{tabular}{|c|c|c|c|}
\hline & 1. $\mathrm{H}_{2} \mathrm{O}$ & $1 \cdot \mathrm{HCl} \cdot 2 \mathrm{H}_{2} \mathrm{O}$ & $1 \cdot \mathrm{HCl} \cdot 6 \mathrm{H}_{2} \mathrm{O}$ \\
\hline $\mathrm{Pt}-\mathrm{Cl}$ & $2.301(1)$ & $\begin{array}{c}2.296(1) \\
2.303(2)\end{array}$ & $2.315(6)$ \\
\hline Pt1-N1 & $2.015(5)$ & $\begin{array}{c}2.030(5) \\
2.014(4)\end{array}$ & $2.00(1)$ \\
\hline Pt1-N2 & $1.935(5)$ & $\begin{array}{l}1.929(4) \\
1.927(5)\end{array}$ & $1.98(1)$ \\
\hline Pt1-N3 & $2.030(5)$ & $\begin{array}{c}2.013(5) \\
2.029(4)\end{array}$ & $2.03(1)$ \\
\hline Pt...Pt & $5.3103(1)$ & $\begin{array}{c}3.3994(4), \\
3.3022(7)\end{array}$ & $\begin{array}{l}3.385(1) \\
3.705(1)\end{array}$ \\
\hline N1-Pt1-N3 & $162.2(2)$ & $\begin{array}{c}162.5(2) \\
162.7(1)\end{array}$ & $162.4(6)$ \\
\hline $\begin{array}{l}\mathrm{Cl} 1-\mathrm{Pt} 1 \cdots \\
\mathrm{Pt} 11^{\prime}-\mathrm{Cl} 1^{\prime}\end{array}$ & 0 & $122.43(5), 180$ & 180 \\
\hline
\end{tabular}

forms, $\mathbf{1}$ and $\mathbf{1} \cdot \mathbf{H C l}$, exhibited remarkably different vapochromic behaviour and reversibly transformed between them by exposure to humid $\mathrm{HCl}$ gas (hereafter abbreviated as $\mathrm{HCl}$ vapour) and dry by heating. Further, the proton conducting and luminescence behaviour of $\mathbf{1} \cdot \mathbf{H C l}$ changed in response to the relative humidity $(\mathrm{RH})$; the proton conductivity was significantly enhanced by increasing the $\mathrm{RH}$ at $298 \mathrm{~K}\left(6.8 \times 10^{-3} \mathrm{~S} \mathrm{~cm}^{-1}\right.$ at $95 \%$ $\mathrm{RH}$ and $298 \mathrm{~K}$ ) and the dark-red emission originating from the triplet metal-metal-to-ligand charge-transfer state ( $\left.{ }^{3} \mathrm{MMLCT}\right)$ clearly changed to bright orange emission at the same $\mathrm{RH}$ region. To the best of our knowledge, these complexes are the first example of switchable vapochromic and highly proton conducting materials that contribute towards the visualization of the proton conducting state.

\section{Results and discussion}

\section{Crystal structures.}

Crystal structures of the deprotonated form $\mathbf{1} \cdot \mathrm{H}_{\mathbf{2}} \mathrm{O}$ and the $\mathrm{HCl}-$ adducted forms $\mathbf{1} \cdot \mathbf{H C l} \cdot \mathbf{2} \mathrm{H}_{2} \mathrm{O}$ and $\mathbf{1} \cdot \mathbf{H C l} \cdot \mathbf{6} \mathrm{H}_{2} \mathrm{O}$ are illustrated in Figure 1. Selected bond lengths and angles are listed in Table 1. Complex 1 was crystalized in the monoclinic $P 2_{1} / c$ space group. In this structure, one $\mathrm{Pt}(\mathrm{II})$ cation, one tpypy ligand, two $\mathrm{Cl}^{-}$ anions, and one water molecule were crystallographically independent. The Pt-N bond distance of the central pyridyl ring (Pt1-N2) was $\sim 0.09 \AA$ shorter than the other $\mathrm{Pt}-\mathrm{N}$ bond distances, a characteristic feature of tpy-bound complexes. The bond lengths around the $\mathrm{Pt}(\mathrm{II})$ ion were near-comparable to those of the carboxy-functionalized analogue complex $[\mathrm{PtCl}(\mathrm{tpyCOOH})] \mathrm{Cl} \quad\left(\mathrm{tpyCOOH}=4^{\prime}\right.$-carboxy-2,2':6', $2^{\prime \prime}$ terpyridine) ${ }^{46}$ suggesting that the replacement of the carboxy functional group attached at the central pyridyl ring with a pyridyl group had negligible effect on the coordination structure of the central $\mathrm{Pt}(\mathrm{II})$ cation. The additional pyridyl group attached at the central pyridyl ring of the tpy ligand was located on the same plane as the planar tpy ligand. Although the near-planar cationic molecules $\left[\mathrm{PtCl}(\text { tpypy) }]^{+}\right.$were stacked along the $a$ axis with relatively short stacking distances (mean distance between two adjacent molecules, $3.30 \AA$ ) , the intermolecular Pt...Pt 
stacking distance (Figure 1(b), 5.3103(1) Å) was significantly longer than twice the length of the van der Waals radius of $\mathrm{Pt}$ (3.50 A). This suggested that the $\pi-\pi$ stacking interaction was effective in this crystal, while the intermolecular Pt...Pt interaction was negligible. Figure 1 (c) illustrates that the counter $\mathrm{Cl}^{-}$anions and hydrated water molecules formed a onedimensional (1-D) hydrogen-bonded chain structure $(\mathrm{O}-\mathrm{H} \cdots \mathrm{Cl}$ : 3.123(5) and 3.126(5) $\AA$, respectively) as well as 1-D Pt(II) complex columns (Figure S1(a)).

In contrast to $\mathbf{1} \cdot \mathbf{H}_{\mathbf{2}} \mathrm{O}$, the $\mathrm{HCl}$-adducted forms $\mathbf{1} \cdot \mathbf{H C l} \cdot \mathbf{2} \mathbf{H}_{2} \mathrm{O}$ and $1 \cdot \mathbf{H C l} \cdot 6 \mathrm{H}_{2} \mathrm{O}$ presented remarkably different crystal structures. $\mathbf{1} \cdot \mathbf{H C l} \cdot \mathbf{2} \mathrm{H}_{2} \mathrm{O}$ crystallized in the triclinic $P$-1 space group, with two $\mathrm{Pt}$ (II) complex molecules, four $\mathrm{Cl}^{-}$anions, and four water molecules being crystallographically independent in the unit cell. On the other hand, $\mathbf{1} \cdot \mathbf{H C l} \cdot \mathbf{6} \mathbf{H}_{\mathbf{2}} \mathbf{O}$ crystallized in the same space group $\left(P 2_{1} / C\right)$ observed for $\mathbf{1} \cdot \mathbf{H}_{2} \mathbf{O}$ and only one $\mathrm{Pt}(\mathrm{II})$ complex molecule, two $\mathrm{Cl}^{-}$anions, and six water molecules were crystallographically independent in the unit cell. The existence of two $\mathrm{Cl}^{-}$anions per one $\mathrm{Pt}(\mathrm{II})$ complex molecule in both $\mathbf{1} \cdot \mathbf{H C l} \cdot \mathbf{2} \mathrm{H}_{2} \mathrm{O}$ and $\mathbf{1} \cdot \mathbf{H C l} \cdot \mathbf{6} \mathrm{H}_{\mathbf{2}} \mathbf{O}$ indicated that the $\mathrm{Pt}(\mathrm{II})$ complex molecule was a divalent cation, whereby the noncoordinating pyridyl $\mathrm{N}$ atom was protonated. The protonated pyridyl $\mathrm{N}$ atoms formed hydrogen bonds with the counter $\mathrm{Cl}^{-}$ anions, with $\mathrm{N}-\mathrm{H} \cdots \mathrm{Cl}$ distances of $\sim 3.023(6) \AA$ for $\mathbf{1} \cdot \mathbf{H C l} \cdot \mathbf{2} \mathbf{H}_{2} \mathbf{O}$ and $3.04(2) \AA ̊$ for $\mathbf{1} \cdot \mathbf{H C l} \cdot \mathbf{6} \mathbf{H}_{\mathbf{2}} \mathbf{O}$. Compared to that in $\mathbf{1} \cdot \mathbf{H}_{\mathbf{2}} \mathbf{O}$, larger torsion angles were observed between the protonated pyridyl rings and central pyridine rings of the tpy moieties $\left(\sim 10^{\circ}\right.$ for $\mathbf{1} \cdot \mathbf{H C l} \cdot 2 \mathrm{H}_{2} \mathrm{O}$ and $25^{\circ}$ for $\mathbf{1} \cdot \mathbf{H C l} \cdot 6 \mathrm{H}_{2} \mathrm{O}$ ). This suggested that the planarity of the $[\mathrm{PtCl}(\mathrm{tpypyH})]^{2+}$ molecule, as compared to that of $[\mathrm{PtCl}(\mathrm{tpypy})]^{+}$, was lowered by protonation. On the other hand, the $\mathrm{Pt}-\mathrm{Cl}$ and $\mathrm{Pt}-\mathrm{N}$ bond distances of the $\mathrm{HCl}$-adducted forms were comparable to those of $\mathbf{1} \cdot \mathbf{H}_{\mathbf{2}} \mathbf{O}$, suggesting that the protonation of the pyridyl group had negligible effect on the coordination environment of the central Pt(II) cation. Interestingly, the $\mathrm{Pt}(\mathrm{II})$ complex molecules were stacked along the $a$ axis in $\mathbf{1} \cdot \mathbf{H C l} \cdot \mathbf{2} \mathrm{H}_{2} \mathbf{O}$ and along the $c$ axis in $\mathbf{1} \cdot \mathbf{H C l} \cdot \mathbf{6} \mathbf{H}_{\mathbf{2}} \mathbf{O}$. Moreover, the intermolecular Pt...Pt distances (Figure 1(b), 3.3022(7) and 3.3994(4) $\AA$ for $\mathbf{1} \cdot \mathbf{H C l} \cdot \mathbf{2} \mathbf{H}_{2} \mathrm{O}$ and 3.385(1) and 3.705(1) $\AA$ for $\mathbf{1} \cdot \mathbf{H C l} \cdot \mathbf{6} \mathbf{H}_{\mathbf{2}} \mathbf{O}$ ) were significantly shorter than that of $\mathbf{1} \cdot \mathbf{H}_{\mathbf{2}} \mathbf{O}(5.3103(1) \AA \AA)$. These stacking distances clearly indicated that the intermolecular Pt...Pt interaction became more effective in the order $\mathbf{1} \cdot \mathbf{H}_{\mathbf{2}} \mathbf{O}<\mathbf{1} \cdot \mathbf{H C l} \cdot \mathbf{6} \mathbf{H}_{\mathbf{2}} \mathbf{O}<\mathbf{1} \cdot \mathbf{H C l} \cdot \mathbf{2} \mathbf{H}_{\mathbf{2}} \mathbf{O}$. Each Pt(II) complex molecule in the 1-D column of $1 \cdot \mathbf{H C l} \cdot 6 \mathrm{H}_{2} \mathrm{O}$ was stacked in an antiparallel orientation as suggested by the (a)

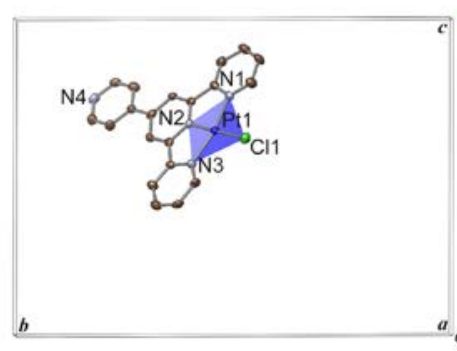

(b) (c)
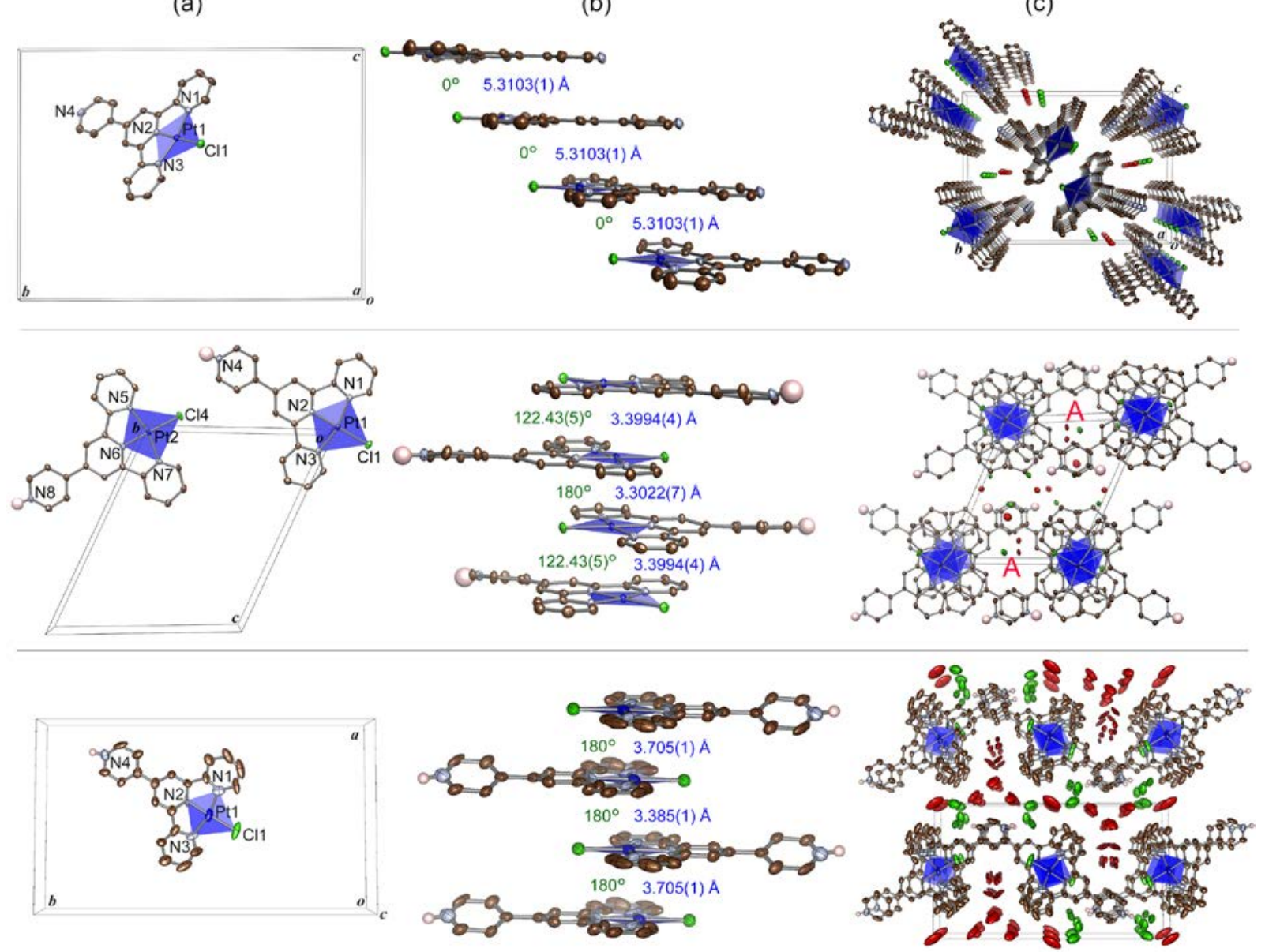

Figure 1. Crystal structures of (top) $\mathbf{1} \cdot \mathbf{H}_{2} \mathbf{O}$, (middle) $\mathbf{1} \cdot \mathbf{H C l} \cdot \mathbf{2} \mathrm{H}_{2} \mathbf{O}$, and (bottom) $\mathbf{1} \cdot \mathbf{H C l} \cdot \mathbf{6} \mathbf{H}_{2} \mathbf{O}$. (a) Crystallographically independent $\mathrm{Pt}(\mathrm{II}) \mathrm{molecule}(\mathrm{s}),(\mathrm{b}) \mathbf{1}-\mathrm{D}$ stacking structures, and (c) packing diagrams viewed along the $a$ axis. Pt(II) coordination planes are depicted as blue squares. Brown, light blue, red, light green, and pink ellipsoids represent the $\mathrm{C}, \mathrm{N}, \mathrm{O}, \mathrm{Cl}$, and $\mathrm{H}$ atoms, respectively. All the $\mathrm{H}$ atoms, except for those bound to the $\mathrm{N}$ atoms, are omitted for clarity. The displacement parameters are drawn at the $50 \%$ probability level. The values in blue and green in panel (b) are the intermolecular Pt...Pt distances and torsion angles (Cl1-Pt1 ..Pt1'-Cl1'). 
$180^{\circ}$ torsion angle in $\mathrm{Cl} 1-\mathrm{Pt} 1 \ldots \mathrm{Pt} 1^{\prime}-\mathrm{Cl} 1^{\prime}$. The cationic pyridinium rings of the $[\mathrm{PtCl}(\mathrm{tpypyH})]^{2+}$ molecules also formed a 1-D stacked columnar structure by weak $\pi-\pi$ stacking interaction between two adjacent $\mathrm{Pt}(\mathrm{II})$ stacking columns, despite the electrostatic repulsion (bottom panel in Figure 1(c)). In contrast, the $\left[\mathrm{PtCl}(\text { tpypyH) }]^{2+}\right.$ stacking in $\mathbf{1} \cdot \mathbf{H C l} \cdot \mathbf{2} \mathbf{H}_{\mathbf{2}} \mathbf{O}$ differed from that of the hexahydrate crystal as suggested by the two different torsion angles along the Pt...Pt stacking axis $\left(122.43(5)^{\circ}\right.$ and $180^{\circ}$, Table 1$)$. Thus, the cationic pyridinium ring in the dihydrate crystal was weakly dimerized via $\pi-\pi$ stacking interaction with the same group of the adjacent molecule at two different positions, resulting in the formation of quasi-1-D small porous channels surrounded by two $\mathrm{Pt}$ (II) columns and two dimerized pyridinium cations (designated as $A$ in the middle panel of Figure 1(c)). Two crystal water molecules per one $\mathrm{Pt}(\mathrm{II})$ cation were observed in the dihydrate crystal between the layers of the $\mathrm{Pt}(\mathrm{II})$ complex columns and small porous A channels to form intermolecular $\mathrm{O}-\mathrm{H} \cdots \mathrm{Cl}-$ and $\mathrm{O}-$ H... O-type hydrogen bonds (Figure S1(b)). Similarly, crystal water molecules (approx. six molecules per one $\mathrm{Pt}$ (II) cation) were also observed in the hexahydrate form between the layers of the $\mathrm{Pt}$ (II) columns to form a more developed hydrogenbonded network structure (Figure $\mathrm{S} 1(\mathrm{c})$ ) with disordering of both the crystal water molecules and counter $\mathrm{Cl}^{-}$anions. Notably, the acidic $\mathrm{N}-\mathrm{H}^{+}$protons in the $\left[\mathrm{PtCl}(\text { tpypyH) }]^{2+}\right.$ cations located in the hydrated water layers of both the dihydrate and hexahydrate forms play a key role in proton conduction.

\section{Photophysical properties.}

Because the $\mathbf{1} \cdot \mathbf{H}_{\mathbf{2}} \mathbf{O}, \mathbf{1} \cdot \mathbf{H C l} \cdot \mathbf{2} \mathbf{H}_{\mathbf{2}} \mathbf{O}$, and $\mathbf{1} \cdot \mathbf{H C l} \cdot \mathbf{6} \mathbf{H}_{\mathbf{2}} \mathbf{O}$ crystals exhibited completely different colours (yellow, dark-red, and orange, respectively), the photophysical properties of these three forms were investigated in detail. Figure 2 displays the excitation and emission spectra of these three forms in the solid state. The photophysical parameters are summarized in Table 2. The complex $\mathbf{1} \cdot \mathbf{H}_{\mathbf{2}} \mathbf{O}$ exhibited yellow emission with the emission maximum at $519 \mathrm{~nm}$ and strong vibronic progressions. The anomaly in the vibronic progressions observed at the longer wavelength region, $\sim 650 \mathrm{~nm}$, was attributed to the partly ground species generated during sample preparation (see below). On the other hand, the $\mathrm{HCl}$ adduct $\mathbf{1} \cdot \mathbf{H C l} \cdot \mathbf{2} \mathbf{H}_{\mathbf{2}} \mathrm{O}$ exhibited dark red emission centred at $741 \mathrm{~nm}$, without vibronic structure. A similar broad band was observed for the hexahydrate form
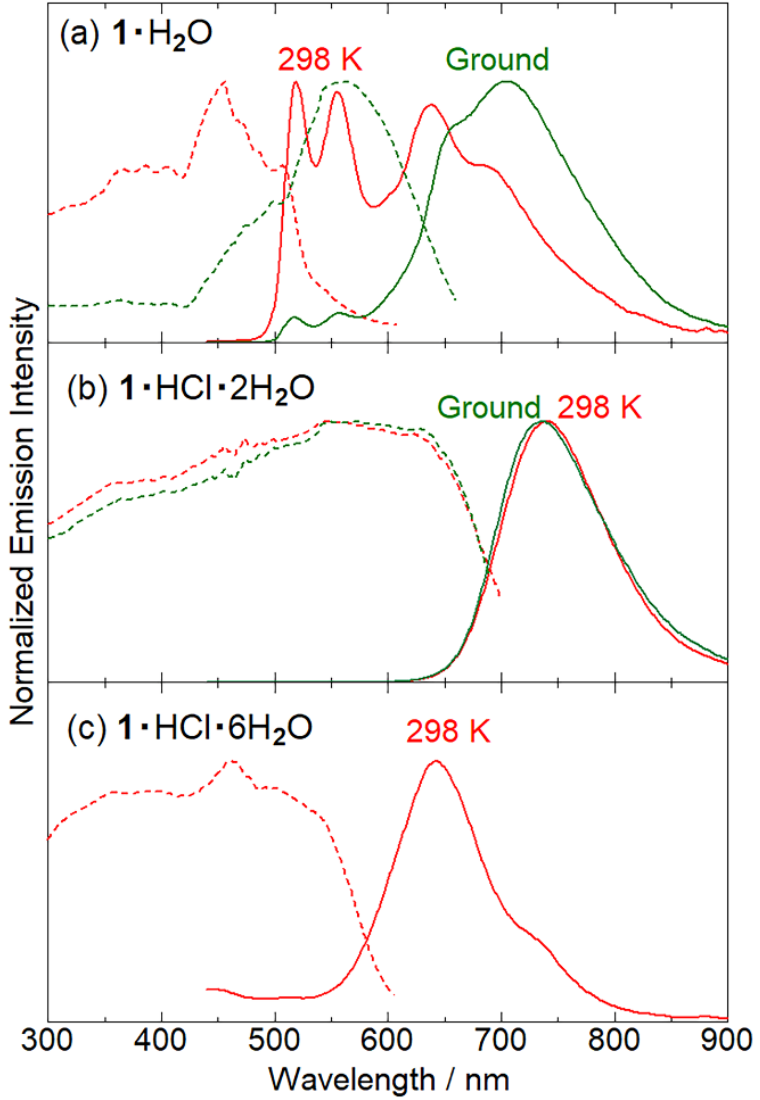

Figure 2. Excitation (dotted lines) and emission (solid lines) spectra of the assynthesized (red) and manually ground (green) (a) $\mathbf{1} \cdot \mathbf{H}_{2} \mathbf{O}$, (b) $\mathbf{1} \cdot \mathbf{H C l} \cdot \mathbf{2} \mathrm{H}_{2} \mathbf{O}$, and (c) 1. $\mathbf{H C l} \cdot 6 \mathrm{H}_{2} \mathrm{O}$ complexes in the solid state at $298 \mathrm{~K}$.

1. $\mathbf{H C l} \cdot 6 \mathrm{H}_{2} \mathbf{O}$ but with the emission maximum blue shifted to 642 $\mathrm{nm}$. A similar difference was also observed in the excitation spectra, whereby the $\mathbf{1} \cdot \mathbf{H}_{\mathbf{2}} \mathbf{O}$ spectrum comprised several sharp peaks, while the broad band extended to 650 and $550 \mathrm{~nm}$ for $\mathbf{1} \cdot \mathbf{H C l} \cdot \mathbf{2} \mathrm{H}_{2} \mathbf{O}$ and $\mathbf{1} \cdot \mathbf{H C l} \cdot \mathbf{6} \mathbf{H}_{2} \mathbf{O}$, respectively. For $\mathbf{1} \cdot \mathbf{H}_{\mathbf{2}} \mathbf{O}$, the observed emission decay was remarkably longer than those of 1. $\mathbf{H C l} \cdot 2 \mathrm{H}_{2} \mathrm{O}$ and $\mathbf{1} \cdot \mathbf{H C l} \cdot 6 \mathrm{H}_{2} \mathrm{O}$ at both 298 and $77 \mathrm{~K}$ (Figure S2), while the emission quantum yields of $\mathbf{1} \cdot \mathbf{H C l} \cdot \mathbf{2} \mathbf{H}_{2} \mathrm{O}$ and 1. $\mathbf{H C l} \cdot 6 \mathrm{H}_{2} \mathrm{O}$ were about four- and six fold higher, respectively, than that of $\mathbf{1} \cdot \mathbf{H}_{\mathbf{2}} \mathrm{O}$ (Table 2 ). These contrasting results indicated the remarkable effect of the protonation occurring at the pyridyl group on the emission behaviour of $\mathbf{1} \cdot \mathbf{H}_{\mathbf{2}} \mathbf{O}$. The time-

Table 2. Photophysical properties of $1 \cdot \mathrm{H}_{2} \mathrm{O}, \mathbf{1} \cdot \mathbf{H C l} \cdot 2 \mathrm{H}_{2} \mathrm{O}$, and $\mathbf{1} \cdot \mathbf{H C l} \cdot 6 \mathrm{H}_{2} \mathrm{O}$ in the solid state.

\begin{tabular}{|c|c|c|c|c|c|c|}
\hline \multirow{2}{*}{$\begin{array}{c}\text { Complex } \\
T / \mathrm{K}\end{array}$} & \multicolumn{2}{|c|}{$1 \cdot \mathrm{H}_{2} \mathrm{O}$} & \multicolumn{2}{|c|}{$1 \cdot \mathrm{HCl} \cdot 2 \mathrm{H}_{2} \mathrm{O}$} & \multicolumn{2}{|c|}{$1 \cdot \mathrm{HCl} \cdot 6 \mathrm{H}_{2} \mathrm{O}$} \\
\hline & 298 & 77 & 298 & 77 & 298 & 77 \\
\hline$\lambda_{\max } / \mathrm{nm}$ & $519,555,637$ & $529,570,643$ & 741 & 779 & 642 & 658 \\
\hline$\tau_{1} / \mathrm{ns}\left(A_{1}\right)^{a}$ & $204(0.843)$ & $1747(0.677)$ & 49.2 & 246 & 93.2 & 2683 \\
\hline$\tau_{2} / \mathrm{ns}\left(A_{2}\right)^{a}$ & $577(0.289)$ & $7387(0.450)$ & - & - & - & - \\
\hline$\tau_{\mathrm{av}}^{b} / \mathrm{ns}$ & 388 & 5907 & - & - & - & - \\
\hline$\Phi$ & 0.016 & 0.049 & 0.061 & 0.13 & 0.095 & 0.36 \\
\hline$k_{\mathrm{r}}^{c} / \mathrm{s}^{-1}$ & $4.1 \times 10^{4}$ & $8.3 \times 10^{3}$ & $1.2 \times 10^{6}$ & $5.3 \times 10^{5}$ & $1.0 \times 10^{6}$ & $1.3 \times 10^{5}$ \\
\hline$k_{\mathrm{nn}}{ }^{d} / \mathrm{s}^{-1}$ & $2.5 \times 10^{6}$ & $1.6 \times 10^{5}$ & $1.9 \times 10^{7}$ & $3.5 \times 10^{6}$ & $9.7 \times 10^{6}$ & $2.4 \times 10^{5}$ \\
\hline
\end{tabular}

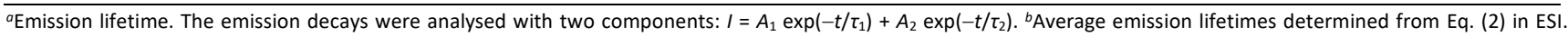
${ }^{c}$ Radiative rate constant $k_{\mathrm{r}}=\Phi / \tau_{\mathrm{av} .}{ }^{d}$ Nonradiative rate constant $k_{\mathrm{nr}}=k_{\mathrm{r}}(1-\Phi) / \Phi$. 
resolved emission spectra of $\mathbf{1} \cdot \mathbf{H}_{\mathbf{2}} \mathbf{O}$ in the different two ranges were almost identical (Figure S3), suggesting the two emission components observed in the emission decay have the same emission origin. Only a slight red shift was observed in the UVvis absorption spectrum of $\mathbf{1} \cdot \mathbf{H}_{\mathbf{2}} \mathrm{O}$ in the $\mathrm{MeOH}$ solution state by the addition of $\mathrm{HCl}$ (Figure S4). This suggested that both the protonation of the pyridyl group and the crystal structure change by $\mathrm{HCl}$ addition are crucial factors for the emission origin. In addition, UV-Vis absorption spectrum of $\mathbf{1} \cdot \mathbf{H C l}$ in the $\mathrm{MeOH}$ solution was almost identical to that of $\mathbf{1}$ (Figure S4), suggesting the proton release in the $\mathrm{MeOH}$ solution because of the high acidity of pyridinium group.

The yellow emission of $\mathbf{1} \cdot \mathbf{H}_{\mathbf{2}} \mathbf{O}$ with remarkable vibrational progression was assigned to ligand-centred triplet $\pi-\pi^{*}$ emission $\left({ }^{3} \pi-\pi^{*}\right)$, as suggested by the crystal structure without intermolecular $\mathrm{Pt}$...Pt interaction. In contrast, the effective intermolecular Pt...Pt interaction of $\mathbf{1} \cdot \mathbf{H C l} \cdot \mathbf{2} \mathrm{H}_{\mathbf{2}} \mathrm{O}$ and $\mathbf{1} \cdot \mathbf{H C l} \cdot \mathbf{6} \mathbf{H}_{\mathbf{2}} \mathrm{O}$ enabled these complexes to exhibit triplet metal-metal-toligand charge transfer ( $\left.{ }^{3} \mathrm{MMLCT}\right)$ emission. These assignments were supported by the emission spectra at $77 \mathrm{~K}$. A similar vibronic structure at the same wavelength region was also observed in the emission spectrum of $\mathbf{1} \cdot \mathbf{H}_{\mathbf{2}} \mathrm{O}$ at $\mathbf{7 7} \mathrm{K}$, whereas obvious red shifts ( 38 and $16 \mathrm{~nm}$ ) were observed for $\mathbf{1} \cdot \mathbf{H C l} \cdot \mathbf{2} \mathrm{H}_{2} \mathrm{O}$ and $\mathbf{1} \cdot \mathbf{H C l} \cdot 6 \mathrm{H}_{2} \mathrm{O}$, respectively, on lowering the temperature to $77 \mathrm{~K}$ (Figure S5). Further, the near-identical spectrum of $\mathbf{1} \cdot \mathbf{H}_{\mathbf{2}} \mathbf{O}$ was also observed in the frozen $\mathrm{MeOH} / \mathrm{EtOH}$ glass states at $77 \mathrm{~K}$ and the emission of the ligand was also observed in the same wavelength region (Figure $\mathrm{S6}$ ).

Interestingly, the emission spectrum of $\mathbf{1} \cdot \mathbf{H}_{\mathbf{2}} \mathbf{O}$ was highly sensitive to mechanical stimulation (Figures 2(a) and S7). The manually ground (mortar and pestle, $5 \mathrm{~min}$ ) $\mathbf{1} \cdot \mathbf{H}_{\mathbf{2}} \mathrm{O}$ exhibited red emission with the emission maximum at $704 \mathrm{~nm}$, which was comparable to the emission maximum of $\mathbf{1} \cdot \mathbf{H C l} \cdot \mathbf{2} \mathbf{H}_{2} \mathbf{O}$ with effective intermolecular Pt...Pt interaction. In contrast, such a marked change by grinding was not observed for $\mathbf{1} \cdot \mathbf{H C l} \cdot \mathbf{2} \mathrm{H}_{2} \mathrm{O}$ (Figures 2(b) and S7). The PXRD pattern of the ground $\mathbf{1} \cdot \mathrm{H}_{2} \mathrm{O}$ was near-identical to that of as-synthesized $\mathbf{1} \cdot \mathbf{H}_{\mathbf{2}} \mathbf{O}$ but with broadening of most of the peaks (Figure S8). TG-DTA analysis revealed that the dehydration temperature of $\mathbf{1} \cdot \mathrm{H}_{\mathbf{2}} \mathrm{O}$ was significantly changed by manual grinding (Figure S9). The manually ground $\mathbf{1} \cdot \mathbf{H}_{\mathbf{2}} \mathrm{O}$ exhibited shorter emission decay and higher emission quantum yield ( $\tau_{\mathrm{av}}=115 \mathrm{~ns}, \Phi=0.055$, Figure S2(a)) than that of as-synthesized $\mathbf{1} \cdot \mathbf{H}_{\mathbf{2}} \mathbf{O}\left(\tau_{\mathrm{av}}=388 \mathrm{~ns}, \Phi=0.016\right.$, Table 2), indicating a faster radiative process like ${ }^{3} \mathrm{MMLCT}$ emission observed for $\mathbf{1} \cdot \mathbf{H C l} \cdot \mathbf{2} \mathbf{H}_{2} \mathbf{O}$ and $\mathbf{1} \cdot \mathbf{H C l} \cdot \mathbf{6} \mathbf{H}_{2} \mathbf{O}$. These results suggested that grinding-induced amorphization would partly occur to form the ${ }^{3} \mathrm{MMLCT}$ emissive species with effective intermolecular Pt...Pt interaction. In contrast to the interesting photophysical properties in solid state, these complexes were non-emissive in solution state probably because of the absence of metallophilic interaction.

\section{Proton conductivity.}

As discussed in the crystal structures section, both $\mathbf{1}$ and $\mathbf{1} \cdot \mathbf{H C l}$ comprised hydrated water molecule(s) and counter $\mathrm{Cl}^{-}$anion(s) that formed hydrogen-bonded network structures with different dimensionalities. Since these networks could be proton conduction pathways, the proton conductivity and water vapour adsorption isotherm measurements at various $\mathrm{RH}$ values were conducted. The samples used in the water vapour adsorption isotherm measurements were dried at $160^{\circ} \mathrm{C}$ for 1 and $90{ }^{\circ} \mathrm{C}$ for $1 . \mathrm{HCl}$ under vacuum to remove all the hydrated water molecules. Under these drying conditions, only the hydrated water molecules were selectively removed, as suggested by the TGA data (Figures S10). The afforded results are presented in Figures $3(\mathrm{a})$ and $3(\mathrm{~b})$. The conductivities of $\mathbf{1}$ and $\mathbf{1} \cdot \mathrm{HCl}$ at $40 \% \mathrm{RH}$ were low $\left(1.2 \times 10^{-7}\right.$ and $1.7 \times 10^{-6} \mathrm{~S} \mathrm{~cm}^{-1}$, respectively) but significantly increased on increasing the $\mathrm{RH}$ to $1.9 \times 10^{-4} \mathrm{~S} \mathrm{~cm}^{-1}$ and $6.8 \times 10^{-3} \mathrm{~S} \mathrm{~cm}^{-1}$ at $95 \% \mathrm{RH}$, respectively. In contrast, the conductivity of $\mathbf{1} \cdot \mathbf{H C l}$ decreased significantly to 9.3 $\times 10^{-10} \mathrm{~S} \mathrm{~cm}^{-1}$ when the $\mathrm{RH}$ was decreased to $0 \%$, indicating the electron insulating nature of $\mathbf{1} \cdot \mathbf{H C l}$. This strong $\mathrm{RH}$ dependence clearly revealed that the hydrated water molecules present in the crystals play a key role in the conductivity behaviour. This observation was also supported by the water vapour adsorption isotherms. In the adsorption process, complex $\mathbf{1}$ adsorbed water vapour in three steps: at $<10 \% \mathrm{RH}, \sim 30 \% \mathrm{RH}$, and $70 \% \mathrm{RH}$ to finally form $\mathbf{1 . 2} \mathrm{H}_{\mathbf{2}} \mathrm{O}$. On the other hand, two-step increases were observed in the isotherm of $1 . \mathbf{H C l}$ at $<10 \% \mathrm{RH}$ and $\sim 60 \%$ $\mathrm{RH}$. This difference clearly indicated that the $\mathrm{HCl}$ adsorption to 1 significantly affected its vapour adsorption properties. As suggested by the crystal structure of $\mathbf{1} \cdot \mathbf{H C l} \cdot \mathbf{6} \mathbf{H}_{\mathbf{2}} \mathrm{O}$, the saturated amount of adsorbed water vapour on $\mathbf{1} \cdot \mathbf{H C l}$ was estimated as $5.9 \mathrm{~mol}$ per one $\mathrm{Pt}$ (II) complex, a value twice as large as that of 1 (2.6 mol per one $\mathrm{Pt}(\mathrm{II})$ complex). This was attributed to the presence of one more hydrophilic $\mathrm{Cl}^{-}$anion in $\mathbf{1} \cdot \mathbf{H C l}$ than in $\mathbf{1}$, as suggested by the hydrogen bond formation of all the $\mathrm{Cl}^{-}$anions (Figure S1). The conductivity of $\mathbf{1} \cdot \mathbf{H C l}$ was about tenfold higher than that of $\mathbf{1}$ in all the measured $\mathrm{RH}$ region, suggesting the contribution of the acidic $\mathrm{N}-\mathrm{H}$ proton of the $[\mathrm{PtCl}(\mathrm{tpypyH})]^{2+}$ cation. The conductivity observed at $95 \% \mathrm{RH}$ for $\mathbf{1} \cdot \mathbf{H C l} \cdot \mathbf{6} \mathrm{H}_{2} \mathrm{O}$ was remarkably high and approached that of the well-known proton conductor, Nafion $117\left(\sim 0.1 \mathrm{~S} \mathrm{~cm}^{-1}\right)^{5,9}$. In addition, the colour of 1. $\mathrm{HCl}$ changed dramatically from orange $(0 \% \mathrm{RH})$ to red $(23 \%$ $\mathrm{RH})$ and finally bright orange (95\% RH) on increasing the $\mathrm{RH}$ (insets of Figures 3(a) and S11(a)), suggesting two-step watervapour-induced structural transformations. To gain further insight into the proton conduction mechanism, the temperature dependence of the conductivity was next evaluated (Figure $\mathrm{S} 11$ (b)). The activation energies of $\mathbf{1} \cdot \mathbf{2} \mathbf{H}_{\mathbf{2}} \mathrm{O}$ and $\mathbf{1} \cdot \mathbf{H C l} \cdot 6 \mathrm{H}_{2} \mathrm{O}$ at $95 \% \mathrm{RH}$ were estimated as 0.30 and $0.19 \mathrm{eV}$, respectively. These relatively low values suggested proton hopping through the hydrogen-bonding network, namely Grotthuss-type proton conduction. The lower activation energy of $\mathbf{1} \cdot \mathbf{H C l} \cdot \mathbf{6} \mathbf{H}_{2} \mathbf{O}$ compared to that of $\mathbf{1} \cdot \mathbf{2} \mathbf{H}_{2} \mathbf{O}$ at $95 \% \mathrm{RH}$ was attributed to the different hydrogen bonding networks, whereby the 3-D hydrogen bonding network structure of $\mathbf{1} \cdot \mathbf{H C l}$ involving the acidic $\mathrm{N}-\mathrm{H}$ proton of the $\left[\mathrm{PtCl}(\text { tpypyH) }]^{2+}\right.$ cation may enhance proton conduction (Figure S1). On the other hand, the activation energy of $\mathbf{1} \cdot \mathbf{H C l} \cdot \mathbf{2} \mathbf{H}_{\mathbf{2}} \mathrm{O}$ at $\mathbf{5 0 \%} \mathrm{RH}$ was significantly increased $(0.39 \mathrm{eV})$, suggesting that the structural transformation of $\mathbf{1} \cdot \mathbf{H C l}$ from the hexahydrate to dihydrate phase should close some of the proton conducting pathways. 

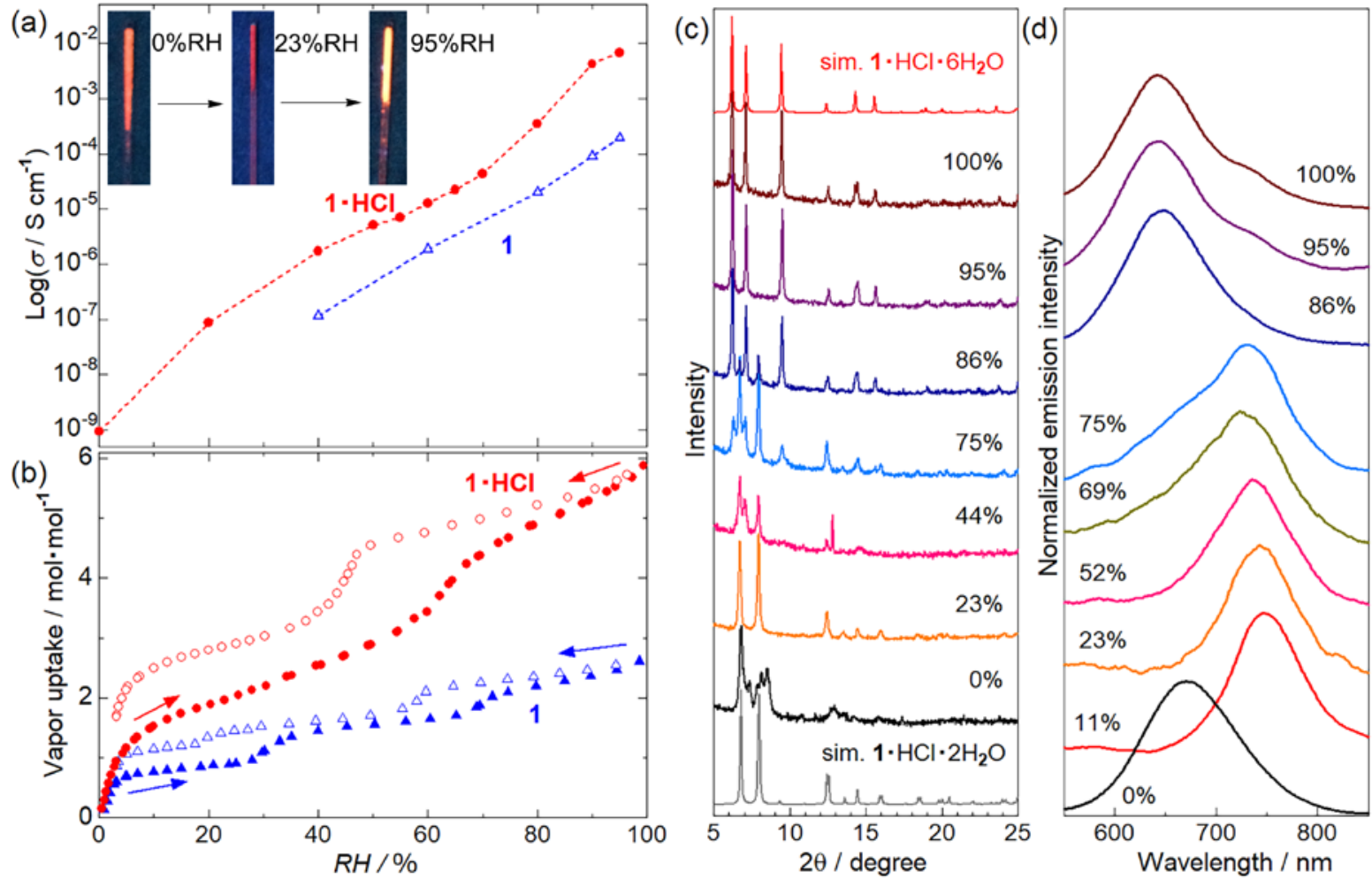

Figure 3. (a) $\log \left(\sigma / \mathrm{S} \mathrm{cm}^{-1}\right)$ vs. RH profiles at $298 \mathrm{~K}$ for $\mathbf{1} \cdot \mathbf{H C l}$ (red closed circles) and $\mathbf{1}$ (blue open triangles). Insets: luminescence images of 1.HCl in $0 \%$ (left), $23 \%$ (center), and $95 \%$ (right) RH. (b) Water vapour adsorption isotherms of $\mathbf{1} \cdot \mathbf{H C l}$ (red circles) and $\mathbf{1}$ (blue triangles) at $298 \mathrm{~K}$. The closed and open symbols in panel (b) represent the adsorption and desorption processes, respectively. (c) RH dependence of the PXRD pattern and (d) emission spectrum $\left(\lambda_{\text {ex }}=400 \mathrm{~nm}\right)$ of $1 \cdot \mathrm{HCl}$ at $293 \mathrm{~K}$.

This is also consistent with the observation that the conductivity of $\mathbf{1} \cdot \mathbf{H C l}$ steeply increased at high $\mathrm{RH}$ regions $(\sim 70 \% \mathrm{RH})$.

In the water vapour desorption process, clear hysteresis was observed for each step, suggesting water-vapour-induced structural transformations. In fact, the PXRD pattern of $\mathbf{1} \cdot \mathbf{H C l}$ clearly changed in two steps (Figure $3(\mathrm{c})$ ). The $\mathbf{1} \cdot \mathbf{H C l}$ patterns in the mid-RH region ( 23 and $44 \% \mathrm{RH}$ ) qualitatively agreed with the simulated pattern based on the crystal structure of the dihydrate phase $\mathbf{1} \cdot \mathbf{H C l} \cdot \mathbf{2} \mathbf{H}_{2} \mathbf{O}$. The data were also consistent with the estimated $\mathrm{X}$-ray diffraction data, which revealed that the number of adsorbed water molecules in the mid-RH region approached the hydration number of $\mathbf{1} \cdot \mathbf{H C l}(2 \mathrm{~mol}$ per one mol of $\mathrm{Pt}(\mathrm{II})$ cation). The PXRD pattern at $0 \% \mathrm{RH}$ was different from the simulation based on the crystal structure of $\mathbf{1} \cdot \mathbf{H C l} \cdot \mathbf{2} \mathrm{H}_{\mathbf{2}} \mathrm{O}$, suggesting the dehydration of $\mathbf{1} \cdot \mathbf{H C l} \cdot \mathbf{2} \mathrm{H}_{2} \mathrm{O}$ gave a significant effect on the crystal structure. In higher $\mathrm{RH}$ region, several diffraction peaks newly appeared at $75 \% \mathrm{RH}$, and then the pattern finally changed to the almost identical one to the simulated $\mathbf{1} \cdot \mathbf{H C l} \cdot \mathbf{6} \mathbf{H}_{\mathbf{2}} \mathbf{O}$, indicating the water-adsorption-induced structure transformation from the dihydrate to the hexahydrate phase. Interestingly, these two-step transformations were further evidenced by the emission spectral changes (Figure 3(d)). Thus, a longer wavelength emission ( $740 \mathrm{~nm})$ was commonly observed in the mid-RH region, whereas shorter wavelength emissions ( $~ 670$ and $640 \mathrm{~nm}$ ) were observed at 0 and $\geq 86 \% \mathrm{RH}$, respectively. The emission of $\mathbf{1} \cdot \mathbf{H C l} \cdot \mathbf{2} \mathbf{H}_{2} \mathrm{O}$ (mid-RH region) was assigned to the ${ }^{3} \mathrm{MMLCT}$ phosphorescence originating from the effective intermolecular Pt...Pt interaction. Thus, the structural transformations of $\mathbf{1} \cdot \mathbf{H C l} \cdot \mathbf{2} \mathbf{H}_{\mathbf{2}} \mathrm{O}$ triggered by water removal or adsorption weaken the intermolecular Pt...Pt interaction, resulting in the blue shift of the ${ }^{3} \mathrm{MMLCT}$ phosphorescence as discussed in "Photophysical Properties" section. This was also supported by the longer intermolecular Pt...Pt distance of $\mathbf{1} \cdot \mathbf{H C l} \cdot \mathbf{6} \mathrm{H}_{2} \mathrm{O}$ over that of $\mathbf{1} \cdot \mathbf{H C l} \cdot \mathbf{2} \mathbf{H}_{2} \mathbf{O}$ (Table 1 ). Such drastic changes in the PXRD patterns and emission spectra were not observed for 1 (Figure S12) because of the lack of intermolecular Pt...Pt interaction in this form. This led to the conclusion that the formation of the $\mathrm{HCl}$ adduct is the key step for complex $\mathbf{1}$ to form the higher proton conductive state in the high $\mathrm{RH}$ region as well as for its water-vapour-induced vapochromic behaviour.

\section{Reversible transformation by $\mathrm{HCl}$ adsorption/desorption.}

We next investigated the structural transformation between 1 and $\mathbf{1} \cdot \mathbf{H C l}$. Figure $4(\mathrm{a})$ illustrates the changes in the PXRD pattern of the as-synthesized $\mathbf{1} \cdot \mathbf{H}_{\mathbf{2}} \mathbf{O}$ yellow powder by exposure to $\mathrm{HCl}$ vapour for $1 \mathrm{~d}$ at $303 \mathrm{~K}$ and subsequent heating at $363 \mathrm{~K}$ for $8 \mathrm{~h}$. The pattern of as-synthesized $\mathbf{1} \cdot \mathbf{H}_{\mathbf{2}} \mathrm{O}$ well-agreed with the simulated pattern calculated from the $\mathbf{1} \cdot \mathbf{H}_{\mathbf{2}} \mathbf{O}$ crystal structure. Interestingly, the PXRD pattern was significantly changed following exposure of the as-synthesized $\mathbf{1} \cdot \mathbf{H}_{\mathbf{2}} \mathbf{O}$ to $\mathrm{HCl}$ vapour at room temperature. The pattern of the $\mathrm{HCl}$-vapourexposed sample did not agree with those of the $\mathbf{1} \cdot \mathbf{H}_{\mathbf{2}} \mathbf{O}$ and 1. $\mathbf{H C l} \cdot 2 \mathrm{H}_{2} \mathrm{O}$ simulations. However, a PXRD pattern that qualitatively agreed with the simulated $\mathbf{1} \cdot \mathbf{H C l} \cdot \mathbf{2} \mathrm{H}_{2} \mathrm{O}$ pattern was attained by subsequent drying at $363 \mathrm{~K}$. Notably, TG-DTA 
(a) $1 \cdot \mathrm{H}_{2} \mathrm{O} \rightarrow 1 \cdot \mathrm{HCl} \cdot 2 \mathrm{H}_{2} \mathrm{O}$

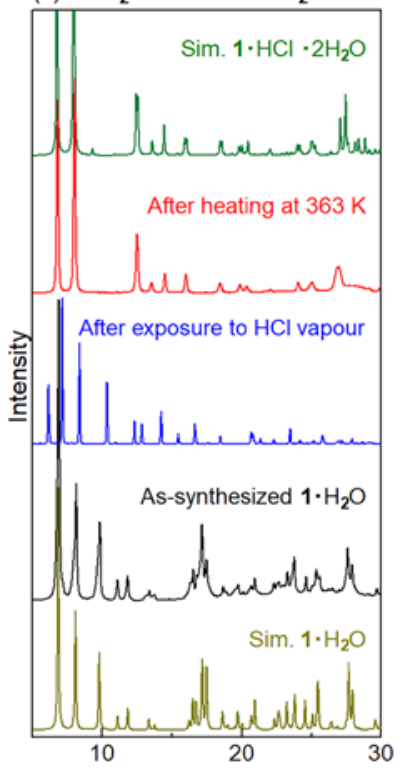

$2 \theta /$ degree

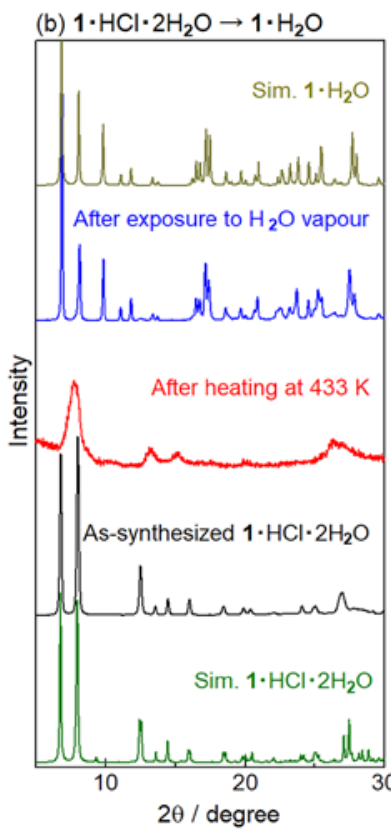

Figure 4. Changes in the PXRD patterns of (a) as-synthesized $\mathbf{1} \cdot \mathrm{H}_{\mathbf{2}} \mathrm{O}$ by exposure to $\mathrm{HCl}$ vapour and subsequent heating at $363 \mathrm{~K}$ and (b) as-synthesized $\mathbf{1} \cdot \mathbf{H C l} \cdot \mathbf{2} \mathbf{H}_{\mathbf{2}} \mathbf{O}$ by heating at $433 \mathrm{~K}$ and subsequent exposure to water vapour. The brown and green patterns of both panels display the simulated patterns based on the crystal structure of $\mathbf{1} \cdot \mathrm{H}_{2} \mathrm{O}$ and $\mathbf{1} \cdot \mathbf{H C l} \cdot 2 \mathrm{H}_{2} \mathrm{O}$, respectively.

analysis revealed that $\mathbf{1} \cdot \mathrm{H}_{\mathbf{2}} \mathrm{O}$ was thermally stable at $\leq 573 \mathrm{~K}$ (Figure $\mathrm{S} 13$ ). Because a conc. $\mathrm{HCl}$ ( $36 \mathrm{wt} \%$ ) aqueous solution was used as the $\mathrm{HCl}$ vapour source in this experiment, co-adsorption of the $\mathrm{H}_{2} \mathrm{O}$ vapour and/or more than one $\mathrm{HCl}$ adsorption per one $\mathrm{Pt}$ (II) complex would be the plausible origins of the disagreement between the simulated $\mathbf{1} \cdot \mathbf{H C l} \cdot \mathbf{2} \mathrm{H}_{2} \mathbf{O}$ and experimental PXRD patterns of the $\mathrm{HCl}$-vapour-exposed 1 . In fact, TG-DTA analysis of $\mathrm{HCl}$-vapour-exposed $\mathbf{1}$ exhibited a larger weight loss than $\mathbf{1} \cdot \mathbf{H C l} \cdot \mathbf{2} \mathbf{H}_{\mathbf{2}} \mathbf{O}$, suggesting that more than one $\mathrm{HCl}$ and two $\mathrm{H}_{2} \mathrm{O}$ molecules per $\mathrm{Pt}$ (II) cation were adsorbed by the as-synthesized $\mathbf{1} \cdot \mathbf{H}_{\mathbf{2}} \mathbf{O}$ (Figure $\mathrm{S} 13$ ). The reverse transformation from the $\mathrm{HCl}$ adduct $\mathbf{1} \cdot \mathbf{H C l} \cdot \mathbf{2} \mathrm{H}_{2} \mathrm{O}$ to the original 1. $\mathrm{H}_{2} \mathrm{O}$ was also examined. Figure $4(\mathrm{~b})$ displays the changes in the PXRD pattern of the as-synthesized $\mathbf{1} \cdot \mathbf{H C l} \cdot \mathbf{2} \mathbf{H}_{\mathbf{2}} \mathbf{O}$ by heating at $433 \mathrm{~K}$ and subsequent water vapour exposure for $1 \mathrm{~d}$. The pattern of the dark red as-synthesized $\mathbf{1} \cdot \mathbf{H C l} \cdot \mathbf{2} \mathbf{H}_{2} \mathbf{O}$ powder was near-identical to the simulated pattern of $\mathbf{1} \cdot \mathbf{H C l} \cdot \mathbf{2} \mathrm{H}_{2} \mathbf{O}$, suggesting the successful synthesis of $\mathbf{1} \cdot \mathbf{H C l} \cdot \mathbf{2} \mathbf{H}_{2} \mathbf{O}$. TG-DTA analysis for $\mathbf{1} \cdot \mathbf{H C l} \cdot \mathbf{2} \mathbf{H}_{2} \mathrm{O}$ clearly revealed that all the solvated molecules (one $\mathrm{HCl}$ and two $\mathrm{H}_{2} \mathrm{O}$ molecules per one $\mathrm{Pt}$ (II) cation) were removed by heating at $433 \mathrm{~K}$ for $6 \mathrm{~h}$ (Figure $\mathrm{S} 10(\mathrm{a})$ ) to form anhydrous 1 . The PXRD pattern of the sample heated at $433 \mathrm{~K}$ comprised few broad diffraction peaks. However, this pattern changed to qualitatively agree with the simulated $\mathbf{1} \cdot \mathbf{H}_{\mathbf{2}} \mathbf{O}$ pattern, following exposure to $\mathrm{H}_{2} \mathrm{O}$ vapour for $1 \mathrm{~d}$ at $303 \mathrm{~K}$. These PXRD patterns clearly revealed that the $\mathrm{HCl}$-adducted $\mathbf{1} \cdot \mathbf{H C l} \cdot \mathbf{2} \mathrm{H}_{2} \mathrm{O}$ was successfully transformed to $\mathbf{1} \cdot \mathbf{H}_{\mathbf{2}} \mathbf{O}$ form via the removal of $\mathrm{HCl}$ and $\mathrm{H}_{2} \mathrm{O}$ molecules by heating at $433 \mathrm{~K}$, and subsequent rehydration by exposure to $\mathrm{H}_{2} \mathrm{O}$ vapour.

\section{Switchable vapochromic behaviour.}

We next investigated the vapochromic behaviour of these two forms, because we predicted that the large difference in their crystal structures would affect their vapour selectivity. Figure 5 depict the changes in the excitation/emission spectra and PXRD patterns of $\mathbf{1} \cdot \mathbf{H}_{\mathbf{2}} \mathrm{O}$ and $\mathbf{1} \cdot \mathbf{H C l} \cdot \mathbf{2} \mathrm{H}_{\mathbf{2}} \mathrm{O}$ by exposure to saturated $\mathrm{H}_{2} \mathrm{O}$, $\mathrm{MeOH}$, and $\mathrm{EtOH}$ vapours at $293 \mathrm{~K}$ for $7 \mathrm{~d}$. The changes in the weak yellow ${ }^{3} \pi-\pi^{*}$ emissions of $\mathbf{1} \cdot \mathbf{H}_{\mathbf{2}} \mathbf{O}$ were negligible under exposure to $\mathrm{H}_{2} \mathrm{O}$ and EtOH vapours. Conversely, a marked change to a broad red emission centred at $670 \mathrm{~nm}$ was observed by exposing $\mathbf{1} \cdot \mathbf{H}_{\mathbf{2}} \mathrm{O}$ to $\mathrm{MeOH}$ vapour. This trend was also observed in the PXRD patterns, whereby a change was only observed under exposure to $\mathrm{MeOH}$ vapour. These results suggest that $\mathbf{1} \cdot \mathbf{H}_{\mathbf{2}} \mathrm{O}$ exhibited vapochromic behaviour selectively with $\mathrm{MeOH}$ vapour. Although the crystal structure of $\mathrm{MeOH}-$ exposed 1 was not elucidated, the broad spectral feature without vibronic progression suggested that the emission origin could have changed from the ${ }^{3} \pi-\pi^{*}$ to the ${ }^{3} \mathrm{MMLCT}$ emission generated by effective Pt...Pt interaction. Such a structural transformation was attributed to $\mathrm{MeOH}$ adsorption to the pyridyl site in $\mathbf{1}$ via $\mathrm{N} \cdots \mathrm{H}-\mathrm{O}$-type hydrogen-bond formation, as suggested by the crystal structure of $\mathbf{1} \cdot \mathbf{H C l} \cdot \mathbf{2} \mathbf{H}_{2} \mathrm{O}$. In fact, the ${ }^{1} \mathrm{H}$ NMR spectrum of $\mathrm{MeOH}$-exposed 1 suggested that two $\mathrm{MeOH}$ molecules per one $\mathrm{Pt}$ (II) cation were adsorbed (Figure S14), while a new band assignable to the hydrogen-bonded $\mathrm{OH}$ group of the adsorbed $\mathrm{MeOH}$ was observed at $3215 \mathrm{~cm}^{-1}$ in the IR spectrum (Figure S15). The original PXRD pattern of $\mathbf{1} \cdot \mathbf{H}_{\mathbf{2}} \mathbf{O}$ was recovered by heating the $\mathrm{MeOH}$-exposed 1 complex at $423 \mathrm{~K}$ (Figure S16), indicating that the $\mathrm{MeOH}$-vapour-induced structural transformation of $\mathbf{1} \cdot \mathbf{H}_{\mathbf{2}} \mathbf{O}$ is reversible.

In contrast to the $\mathrm{MeOH}$ selective vapochromic behaviour of 1. $\mathrm{H}_{2} \mathrm{O}$, the red ${ }^{3} \mathrm{MMLCT}$ emission band of the $\mathrm{HCl}$-adducted form $\mathbf{1} \cdot \mathbf{H C l} \cdot 2 \mathrm{H}_{2} \mathbf{O}(741 \mathrm{~nm})$ was clearly blue-shifted by exposing to $\mathrm{MeOH}$ as well as EtOH and $\mathrm{H}_{2} \mathrm{O}$ vapours. The PXRD patterns of these vapour-exposed samples exhibited completely different patterns to that of the as-synthesized $\mathbf{1} \cdot \mathbf{H C l} \cdot \mathbf{2} \mathbf{H}_{\mathbf{2}} \mathbf{O}$, suggesting vapour-induced structural transformations. Notably, the observed PXRD pattern under $\mathrm{H}_{2} \mathrm{O}$ vapour exposure was near-identical to the simulation calculated from the crystal structure of $\mathbf{1} \cdot \mathbf{H C l} \cdot \mathbf{6} \mathrm{H}_{\mathbf{2}} \mathrm{O}$, indicating the formation of the hexahydrate under highly humid conditions. Further, the original $\mathbf{1} \cdot \mathbf{H C l} \cdot \mathbf{2} \mathbf{H}_{2} \mathrm{O}$ PXRD pattern was successfully recovered by drying these vapour-exposed samples at $363 \mathrm{~K}$ for $8 \mathrm{~h}$ (Figure S17). Thus, we concluded that $\mathbf{1} \cdot \mathbf{H C l} \cdot \mathbf{2} \mathbf{H}_{2} \mathrm{O}$ was a vapochromic complex that responded to these hydrophilic vapours and the blue shift of the emission band was ascribed to the weaker intermolecular Pt...Pt interaction than the original $\mathbf{1} \cdot \mathbf{H C l} \cdot \mathbf{2} \mathrm{H}_{2} \mathrm{O}$ as evidenced by the crystal structure of $\mathbf{1} \cdot \mathbf{H C l} \cdot \mathbf{6} \mathbf{H}_{\mathbf{2}} \mathbf{O}$. Interestingly, the vapochromic shifts caused by the $\mathrm{MeOH}$ and $\mathrm{H}_{2} \mathrm{O}$ vapours (114 and $99 \mathrm{~nm}$, respectively) were significantly larger than that observed with the EtOH vapour $(56 \mathrm{~nm})$. The ${ }^{1} \mathrm{H}$ NMR spectra of the $\mathrm{MeOH}$ - and EtOH-vapour-exposed $1 \cdot \mathbf{H C l}$ suggested that one $\mathrm{MeOH}$ per $\mathrm{Pt}(\mathrm{II})$ cation was adsorbed by 1. $\mathrm{HCl}$, while the adsorbed amount of EtOH was approximately a third of the $\mathrm{MeOH}$ amount (Figure S18). The saturated adsorption amount of $\mathrm{H}_{2} \mathrm{O}$ vapour was also estimated, from the vapour adsorption isotherm, to be significantly larger than the values of the other two vapours $(5.9 \mathrm{~mol}$ per one $\mathrm{Pt}(\mathrm{II})$ 
<smiles></smiles>

(a)

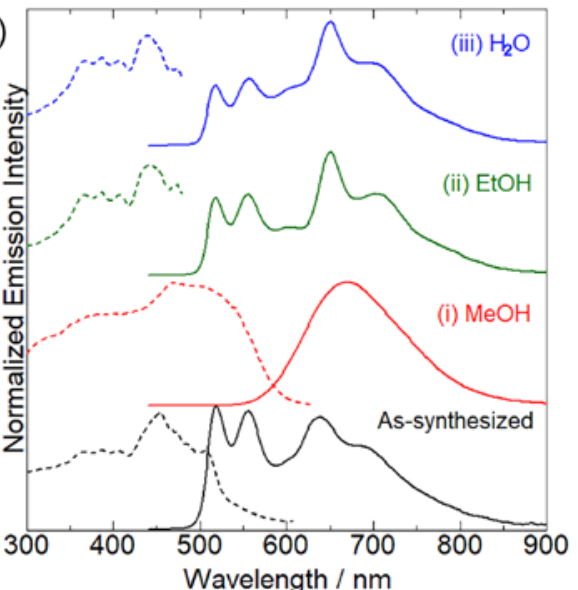

(c)

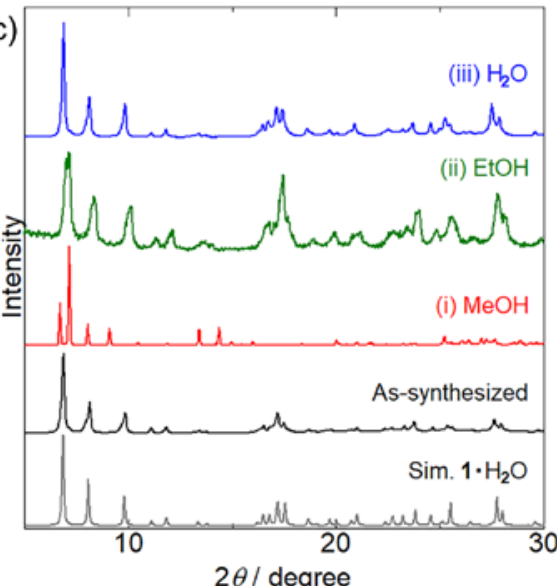<smiles></smiles>

(b)

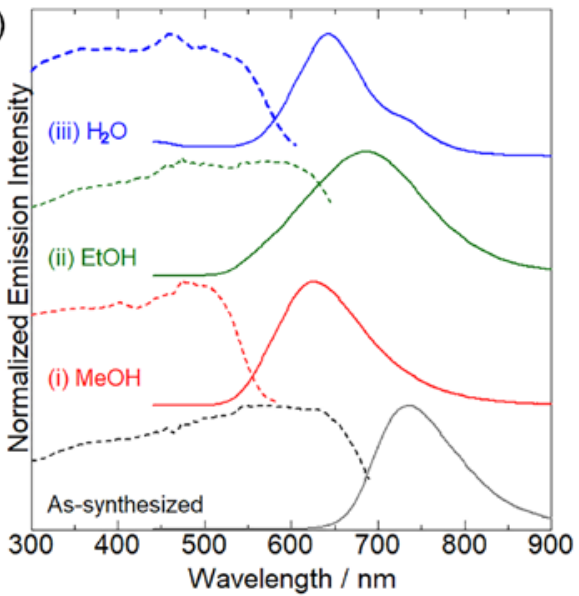

(d)

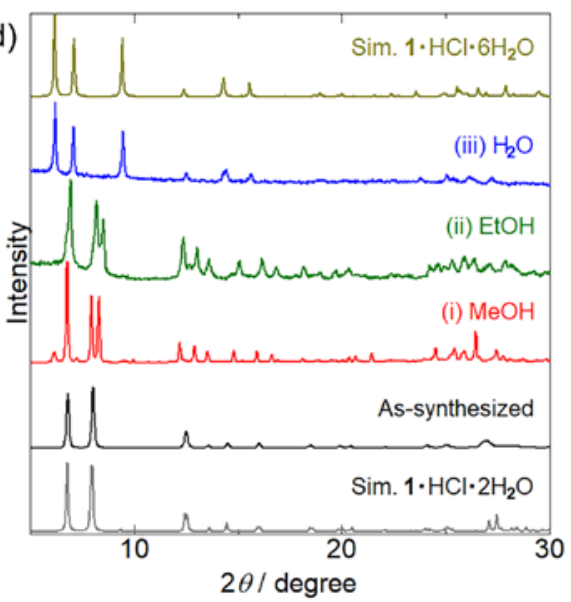

Figure 5. Changes in the $(\mathrm{a}, \mathrm{b})$ excitation and emission spectra $\left(\lambda_{\text {ex }}=400 \mathrm{~nm}\right)$ and $(\mathrm{c}, \mathrm{d}) \mathrm{PXRD}$ patterns of (top) as-synthesized $\mathbf{1} \cdot \mathrm{H}_{\mathbf{2}} \mathrm{O}$ and $(\mathrm{bottom}) \mathbf{1} \cdot \mathbf{H C l} \cdot \mathbf{2} \mathrm{H}_{2} \mathbf{O}$ under exposure to (i, red lines) $\mathrm{MeOH}$, (ii, green lines) $\mathrm{EtOH}$, and (iii, blue lines) $\mathrm{H}_{2} \mathrm{O}$ vapour at $293 \mathrm{~K}$ for $7 \mathrm{~d}$. The bottom black and gray lines in (c, d) are the experimental patterns of the assynthesized samples and the simulations calculated from the crystal structures, respectively. The top line in panel (d, bottom) is the simulation calculated from the crystal structure of the hexahydrate $\mathbf{1} \cdot \mathbf{H C l} \cdot 6 \mathrm{H}_{2} \mathrm{O}$.

molecule; "Proton conduction" section) as suggested by the near-identical PXRD and simulated $\mathbf{1} \cdot \mathbf{H C l} \cdot \mathbf{6} \mathbf{H}_{2} \mathrm{O}$ patterns. Thus, the smaller vapochromic shift observed for the EtOH-vapourexposed $\mathbf{1} \cdot \mathbf{H C l}$ was attributed to the smaller amount of EtOH vapour molecules adsorbed into the crystal lattice of $\mathbf{1 \cdot H C l}$. These results indicated that $\mathrm{HCl}$ adsorption at the pyridyl group of 1 significantly changed the vapour selectivity.

\section{Conclusions}

In this work, we newly synthesized a luminescent Pt(II) complex with a pyridyl-functionalized tpy ligand, $[\mathrm{PtCl}($ tpypy) $] \mathrm{Cl}(\mathbf{1})$ and its $\mathrm{HCl}$ adduct $[\mathrm{PtCl}(\mathrm{tpypyH})] \mathrm{Cl}_{2}(\mathbf{1} \cdot \mathbf{H C l})$ to develop a cooperative phenomenon between proton conduction and vapochromism. The intermolecular Pt...Pt interaction was negligible in $\mathbf{1} \cdot \mathbf{H}_{\mathbf{2}} \mathbf{O}$ but effective in the $\mathrm{HCl}$ adduct $\mathbf{1} \cdot \mathbf{H C l}$ and that the degree of the interaction could be modified by altering the hydration number. Both 1 and $\mathbf{1} \cdot \mathbf{H C l}$ exhibited strong $\mathrm{RH}$-dependent proton conductivity. Notably, the $\mathrm{HCl}$ adduct $\mathbf{1} \cdot \mathbf{H C l}$ exhibited not only clear vapochromic behaviour in response to the $\mathrm{RH}$, but also significantly high conductivity $\left(6.8 \times 10^{-3} \mathrm{~S} \mathrm{~cm}^{-1}\right)$ at $95 \% \mathrm{RH}$, that was significantly higher than that of already reported luminescent $\mathrm{Pt}$ (II) complexes and approaching that of the wellknown proton conductor Nafion. Further, the transformation between $\mathbf{1} \cdot \mathbf{H}_{\mathbf{2}} \mathbf{O}$ and $\mathbf{1} \cdot \mathbf{H C l} \cdot \mathbf{2} \mathbf{H}_{\mathbf{2}} \mathbf{O}$ occurred reversibly by exposure to $\mathrm{HCl}$ and thermal drying. The vapochromic behaviour of these two complexes were completely different: $\mathbf{1} \cdot \mathrm{H}_{\mathbf{2}} \mathrm{O}$ exhibited vapochromism only under exposure to $\mathrm{MeOH}$ vapour, while 1. $\mathbf{H C l} \cdot 2 \mathrm{H}_{2} \mathrm{O}$ displayed vapochromic behaviour in response to several hydrophilic vapours including $\mathrm{MeOH}$ and $\mathrm{EtOH}$. To the best of our knowledge, complex $\mathbf{1} \cdot \mathbf{H C l}$ is the first highly proton conducting and switchable vapochromic material regulated by $\mathrm{HCl}$ desorption/adsorption. We believe that this type of cooperation between vapochromism and proton conduction allows the visualization of the proton conducting pathway, without the need for a bulk electrode, via the absorption and emission colours at both the macroscopic and microscopic levels. Further study to synthesize highly proton conducting vapochromic materials is underway.

\section{Conflicts of interest}


There are no conflicts to declare.

\section{Acknowledgements}

This study was supported by the ENEOS Hydrogen Trust Fund and JSPS KAKENHI, Grant Numbers JP18K19086 and JP17H06367. The PXRD measurements were performed under the approval of the Photon Factory Program Advisory Committee (Proposal No. 2017G528).

\section{Notes and references}

1 K.-D. Kreuer, A. Rabenau, W. Weppner, Angew. Chem. Int. Ed., 1982, 21, 208-209.

2 G. Alberti, M. Casciola, Solid State lonics, 2001, 145, 3-16.

3 K.-D. Kreuer, S. J. Paddison, E. Spohr, M. Schuster, Chem. Rev., 2004, 104, 4637-4678.

4 L. Malavasi, C. A. J. Fisher, M. S. Islam, Chem. Soc. Rev., 2010, 39, 4370-4387.

5 J. Halim, F. N. Büchi, O. Haas, M. Stamm, G. G. Scherer, Electrochim. Acta, 1994, 39, 1303-1307.

6 Q. Li, R. He, J. O. Jensen, N. J. Bjerrum, Chem. Mater., 2003, 15, 4896-4915.

7 S. Long, D. R. MacFarlane, M. Forsyth, Solid State Ionics, 2003 161, 105-112.

8 A. Noda, A. B. Susan, K. Kudo, S. Mitsushima, K. Hayamizu, M. Watanabe, J. Phys. Chem. B, 2003, 107, 4024-4033.

9 K. A. Mauritz, R. B. Moore, Chem. Rev., 2004, 104, 4535-4586.

10 M. Yoon, K. Suh, H. Kim, Y. Kim, N. Selvapalam, K. Kim, Angew. Chem. Int. Ed., 2011, 50, 7870-7873.

11 J. Luo, A. H. Jensen, N. R. Brooks, J. Sniekers, M. Knipper, D. Aili, Q. Li, B. Vanroy, M. Wübbenhorst, F. Yan, L. V. Meervelt,Z. Shao, J. Fang, Z.-H. Luo, D. E. De Vos, K. Binnemans, J. Fransaer, Energy Environ. Sci., 2015, 8, 1276-1291.

12 A. Karmakar, R. Illathvalappil, B. Anothumakkool, A. Sen, P. Samanta, A. V. Desai, S. Kurungot, S. K. Ghosh, Angew. Chem Int. Ed.I, 2016, 55, 10667-10671.

13 M. Liu, L. J. Chen, S. Lewis, S. Y. Chong, M. A. Little, T. Hasell, I. M. Aldous, C. M. Brown, M. W. Smith, C. A. Morrison, L. J. Hardwick, A. I. Cooper, Nat. Commun., 2016, 7, 12750.

14 A. S. Nowick, Y. Du, Solid State lonics, 1995, 77, 137-147.

15 H. G. Bohn, T. Schober, J. Am. Ceram. Soc., 2000, 83, 768-772.

16 K. -D. Kreuer, S. Adams, W. Munch, A. Fuchs, U. Klock, J. Maier, Solid State lonics, 2001, 145, 295-306.

17 K. D. Kreuer, Annu. Rev. Mater. Res., 2003, 33, 333-359.

18 P. Babilo, S. M. Hailew, J. Am. Ceram. Soc., 2005, 88, 23622368.

19 F. Iguchi, T. Tsurui, N. Sata, Y. Nagao, H. Yugami, Solid State lonics, 2009, 180, 563-568.

20 S. Bureekaew, S. Horike, M. Higuchi, M. Mizuno, T. Kawamura, D. Tanaka, N. Yanai, S. Kitagawa, Nat. Mater., 2009, 8, 831836

21 P. Ramaswamy, N. E. Wong, G. K. H. Shimizu, Chem. Soc. Rev., 2014, 43, 5913-5932.

22 J. Canivet, A. Fateeva, Y. Guo, B. Coasne, D. Farrusseng, Chem. Soc. Rev., 2014, 43, 5594-5617.

23 D. Samanta, P. S. Mukherjee, Chem. Eur. J., 2014, 20, 1248312492.

24 W. J. Phang, H. Jo, W. R. Lee, J. H. Song, K. Yoo, B. S. Kim, C. S Hong, Angew. Chem. Int. Ed., 2015, 54, 5142-5146.

25 Q.-G. Zhai, C. Mao, X. Zhao, Q. Lin, F. Bu, X. Chen, X. Bu, P. Feng, Angew. Chem. Int. Ed., 2015, 54, 7886-7890.

26 M. Tadokoro, Y. Ohata, Y. Shimazaki, S. Ishimaru, T. Yamada, Y. Nagao, T. Sugaya, K. Isoda, Y. Suzuki, H. Kitagawa, H. Matsui, Chem. Eur. J., 2014, 20, 13698-13709.
27 T. Kundu, A. K. Jana, S. Natarajan, Cryst. Growth Des., 2014, $14,4531-4544$

28 S. Tominaka, F. X. Coudert, T. D. Dao, T. Nagao, A. K. Cheetham, J. Am. Chem. Soc., 2015, 137, 6428-6431.

29 A. Watanabe, A. Kobayashi, E. Saitoh, Y. Nagao, Y. Yoshida, M. Kato, Inorg. Chem., 2015, 54, 11058-11060.

30 H. B. Luo, L.-T. Ren, W.-H. Ning, S.-X. Liu, J. L. Liu, X.-M. Ren, Adv. Mater., 2016, 28, 1663-1667.

31 K. Fujie, H. Kitagawa, Coord. Chem. Rev., 2016, 307, 382-390.

32 Y. Ye, W. Guo, L. Wang, Z. Li, Z. Song, J. Chen, Z. Zhang, S. Xiang, B. Chen, J. Am. Chem. Soc., 2017, 139, 15604-15607.

33 G. Daigre, J. Cuny, P. Lemoine, M. Amela-Cortes, S. Paofai, N. Audebrand, A. Le Gal La Salle, E. Quarez, S. Joubert, N. G. Naumov, S. Cordier, Inorg. Chem., 2018, 57, 9814-9825.

34 R. M. P. Colodrero, K. E. Papathanasiou, N. Stavgianoudaki, R. Olivera-Pastor, E. R. Losilla, M. A. G. Aranda, L. León-Reina, L. Sanz, I. Sobrados, D. Choquesillo-Lazarte, J. M. García-Ruiz, P. Atienzar, F. Rey, K. D. Demadis, A. Cabeza, Chem. Mater., 2012, 24, 3780-3792.

35 Q. Tang, Y. Liu, S. Liu, D. He, J. Miao, X. Wang, G. Yang, Z. Shi, Z. Zheng, J. Am. Chem. Soc., 2014, 136, 12444-12449.

36 X.-Y. Dong, R. Wang, J.-Z. Wang, S.-Q. Zang, T. C. W. Mak, J. Mater. Chem. A, 2015, 3, 641-647.

37 Y.-S. Wei, X.-P. Hu, Z. Han, X.-Y. Dong, S.-Q. Zang, T. C. W. Mak, J. Am. Chem. Soc., 2017, 139, 3505-3512.

38 W.-W. Zhang, Y.-L. Wang, Q. Liu, Q.-Y. Liu, Inorg. Chem., 2018, 57, 7805-7814.

39 D. Garcia-Fresnadillo, M. D. Marazuela, M. C. Moreno-Bondi, G. Orellana, Langmuir, 1999, 15, 6451-6459.

40 S. J. Glenn, B. M. Cullum, R. B. Nair, D. A. Nivens, C. J. Murphy, S. M. Angel, Anal. Chim. Acta, 2001, 448, 1-8.

41 R. Matsushima, N. Nishimura, Y. Kohno, Chem. Lett., 2003, 32 , 260-261.

42 M. Kato, Bull. Chem. Soc. Jpn., 2007, 80, 287-294.

43 X. Zhang, B. Li, Z.-H. Chen, Z.-N. Chen, J. Mater. Chem., 2012, 22, 11427-11441.

44 O. S. Wenger, Chem. Rev., 2013, 113, 3686-3733.

45 A. Kobayashi, M. Kato, Eur. J. Inorg. Chem., 2014, 4469-4483.

46 A. Kobayashi, S. Oizumi, M. Yoshida, M. Kato, Dalton Trans., 2016, 45, 17485-17494.

47 M. Kato, H. Ito, M. Hasegawa, K. Ishii, Chem. Eur. J., 2019, 25, 5105-5112.

48 S. Kishi, M. Kato, Mol. Cryst. Liq. Cryst., 2002, 379, 303-308.

49 C. Cuerva, J. A. Campo, M. Cano, J. Sanz, I. Sobrados, V. DiezGómez, A. Rivera-Calzada, R. Schmidt, Inorg. Chem., 2016, 55, 6995-7002.

50 C. Chakraborty, U. Rana, R. K. Pandey, S. Moriyama, M. Higuchi, ACS Appl. Mater. Interfaces, 2017, 9, 13406-13414.

51 C. Cuerva, J. A. Campo, M. Cano, R. Schmidt, C. Lodeiro, J. Mater. Chem. C, 2018, 6, 9723-9733. 